\title{
Long-Term Neurodevelopmental and Functional Outcomes of Infants Born Very Preterm and/or with a Very Low Birth Weight
}

\author{
Jonneke J. Hollanders ${ }^{a}$ Nina Schaëfer ${ }^{a}$ \\ Sylvia M. van der Pal ${ }^{\text {b Jaap Oosterlaan }}{ }^{\mathrm{c}}$ Joost Rotteveel ${ }^{\mathrm{a}}$ \\ Martijn J.J. Finken ${ }^{\mathrm{a}}$ on behalf of the Dutch POPS-19 Collaborative Study Group \\ ${ }^{a}$ Department of Pediatrics, VU University Medical Center, Amsterdam, The Netherlands; ${ }^{\text {TNO }}$, Child Health, \\ Leiden, The Netherlands; ' ${ }^{\text {Department }}$ of Clinical Neuropsychology, VU University Amsterdam, Amsterdam, The \\ Netherlands
}

\section{Keywords}

Prematurity · Low gestational age $\cdot$ Adolescents $\cdot I Q \cdot$

Behavior · Health status · Neuromotor functioning

\begin{abstract}
Background: Birth weight (BW) is often used as a proxy for gestational age (GA) in studies on preterm birth. Recent findings indicate that, in addition to perinatal outcomes, subjects born very preterm (VP; GA $<32$ weeks) differ from those with a very low birth weight (VLBW; $B W<1,500 \mathrm{~g}$ ) in postnatal growth up to their final height. Objective: To study whether neurodevelopmental and functional outcomes at the age of 19 years differ in VP and/or VLBW subjects. Methods: 705 19-year-old subjects from the Project on Preterm and Small-for-Gestational-Age Infants (POPS) cohort were classified as (1) VP+/VLBW+ $(n=354),(2) \mathrm{VP}+/ \mathrm{VLBW}-(n=$ 144), or (3) VP-/VLBW+ $(n=207)$, and compared with regard to IQ as assessed with the Multicultural Capacity Test-intermediate level; neuromotor function using Touwen's examination of mild neurologic dysfunction; hearing loss; self- and parent-reported behavioral and emotional functioning; educational achievement and occupation; and self-assessed health using the Health Utilities Index and the London Handicap Scale. Results: VP+/VLBW- infants, on average, had
\end{abstract}

3.8-point higher IQ scores (95\% confidence interval [CI] 0.57.1), a trend towards higher educational achievement, 3.3$\mathrm{dB}$ better hearing (95\% Cl 1.2-5.4), and less anxious behavior, attention problems, and internalizing behavior than to VP+/VLBW+ subjects. VP-/VLBW+ infants reported 1.8 increased odds (95\% Cl 1.2-2.6) of poor health compared to VP+/VLBW+ subjects. Conclusions: At the age of 19 years, subjects born VP+/VLBW+, VP+/VLBW-, and VP-/VLBW+ have different neurodevelopmental and functional outcomes, although effect sizes are small. Hence, the terms VP and VLBW are not interchangeable. We recommend, at least for industrialized countries, to base inclusion in future studies on preterm populations on GA instead of on BW.

(c) 2018 The Author(s)
Published by S. Karger AG, Basel

\section{Introduction}

Being born very preterm (VP; i.e., a gestational age [GA] of $<32$ weeks) and/or with a very low birth weight (VLBW; i.e., a birth weight $[\mathrm{BW}]<1,500 \mathrm{~g}$ ) requires admission to a neonatal intensive care unit (NICU). Both entities have previously been associated with neurodevelopmental and functional problems in adolescence [1-9]. Despite their close resemblance, in contrast to VP birth,

\begin{tabular}{ll}
\hline KARGER & $\begin{array}{l}\text { C } 2019 \text { The Author(s) } \\
\text { Published by S. Karger AG, Basel }\end{array}$ \\
E-Mail karger@karger.com & This article is licensed under the Creative Commons Attribution- \\
www.karger.com/neo & $\begin{array}{l}\text { NonCommercial-NoDerivatives 4.0 International License (CC BY- } \\
\text { NC-ND) (http://www.karger.com/Services/OpenAccessLicense). } \\
\text { Usage and distribution for commercial purposes as well as any dis- } \\
\text { tribution of modified material requires written permission. }\end{array}$
\end{tabular}

Jonneke J. Hollanders, MD

Department of Pediatrics, VU University Medical Center

Room KTC 4.033, Postbus 7057

NL-1007 MB Amsterdam (The Netherlands)

E-Mail j.hollanders@vumc.nl 
VLBW can be attributed to prematurity, intrauterine growth restriction (IUGR), or both.

Results of studies in infants with VLBW are often extrapolated to preterm populations, and vice versa. However, previous research has shown that short-term outcomes are significantly different between children born VP and/or with VLBW, with more neonatal morbidities in VP infants, and more small-for-GA (SGA) births among those with VLBW [10]. Moreover, long-term outcomes also appear to differ, as we recently found that VP and VLBW subjects have significantly different growth patterns and final height [11]. Subjects born VP without VLBW attained a height close to the population reference mean, whereas those with VLBW remained approximately $1 \mathrm{SD}$ shorter despite initial catch-up growth. Whether such differences between VP and VLBW subjects also translate into different long-term neurodevelopmental and functional outcomes is unknown.

In the past three decades, NICU care has improved dramatically and survival rates of infants born VP and/or with VLBW have increased substantially [12]. Among the improvements are the widespread application of antenatal glucocorticoid therapy, the introduction of synthetic surfactant, and a tendency towards more aggressive feeding strategies, although regional differences in the treatment of VP and VLBW infants do exist [13]. Therefore, the entities VP and VLBW can only be compared between populations that have received the same care.

We aimed to compare neurodevelopmental and functional outcomes in adolescence between subjects born VP and/or with VLBW, using the data from the Project on Preterm and Small-for-Gestational-Age Infants (POPS) cohort. This cohort project is, to our knowledge, the only one which studied subjects born both VP and/or with VLBW into adolescence.

\section{Methods}

\section{Population}

The POPS cohort included $94 \%(n=1,338)$ of the infants born alive in 1983 in The Netherlands who were VP and/or had a VLBW. We could therefore distinguish between: (1) VP+/VLBW+, (2) $\mathrm{VP}+/ \mathrm{VLBW}-$, and (3) VP-/VLBW+ infants. Subjects were followed up throughout childhood until the age of 19 years, when the data for this study were collected.

\section{Neurodevelopmental Outcomes}

Cognitive Functioning

Cognitive functioning was quantified with the IQ measured with the Multicultural Capacity Test (MCT)-intermediate level [14]. The MCT has been validated for individuals aged $\geq 16$ years from different ethnic backgrounds with an education ranging from five years of secondary school to university level. It assesses verbal and numerical intelligence, spatial visualization, speech fluency, memory, reasoning, and speed of perception. Four subscales (linguistic capacity, mathematical capacity, logical reasoning, and spatial visualization) and a total score can be derived. Normative scores were expressed on a scale with a mean of 100 and a standard deviation of 15 , based on the Dutch norm population.

\section{Neuromotor Function}

Neuromotor function was assessed with the revised version of Touwen's examination of minor neurologic dysfunction $[15,16]$. It examines 5 subcategories (hand function, quality of walking, coordination, posture, and passive muscle tone), and comprises 34 items, which are scored on a 3 -point scale where 2 = "optimal performance," 1 = "slightly reduced performance," and 0 = "poor performance." Total scores range between 0 and 68 .

Hearing

Hearing was assessed with pure-tone audiometry with a handheld audiometer for each ear separately. Auditory sensitivity was determined as the mean of the threshold levels at 500, 1,000, 2,000, and 4,000 Hz. Hearing loss in the best and worst ear was recorded.

Behavioral and Emotional Functioning

Behavior was studied with the self-reported Young Adult Self Report (YASR), and the parent/caretaker-reported Young Adult Behavior Checklist (YABCL). Both questionnaires were developed by Achenbach [17], and provide standardized scores on behavior, feelings, thoughts, and competences in people aged 18-30 years. The YASR contains 130 items, and the YABCL contains 109 items. Informants are required to rate items pertaining to the past six months, scored as $0=$ "not true," $1=$ "sometimes true," and $2=$ "very often or often true." Eight syndrome scales can be derived: Anxious/depressed, Withdrawn, Somatic complaints, Thought problems, Attention problems, Intrusive behavior, Aggressive behavior, and Delinquent behavior. In addition, 3 problem scales can be calculated: "Internalizing behavior" is the sum of the syndrome scales Anxious/depressed and Withdrawn; Aggressive behavior, Delinquent behavior, and Intrusive behavior comprise the problem scale "Externalizing behavior"; and the "Total problems scale" is the sum of all individual items.

\section{Functional Outcomes}

Educational Achievement

A self-report was used to assess past and current education. Responses were coded according to the highest level of education achieved or currently enrolled, using a revised version of The Netherlands Central Bureau of Statistics (CBS) classification [18]: no/primary education or special education (level 0 ); preparatory vocational education (level 1); intermediate vocational education or higher general secondary education (level 2); and higher vocational education, preuniversity secondary education, or university (level 3). For some participants, responses allowed multiple codings for current education. In such cases, best- and worst-case coding was used, coded by two assessors. Consensus about discrepancies was reached through discussion. Both worst- and best-case classifications were analyzed. 
Table 1. Perinatal characteristics of the 3 groups and the nonresponders

\begin{tabular}{|c|c|c|c|c|c|c|}
\hline & $\begin{array}{l}\mathrm{VP}+/ \mathrm{VLBW}+ \\
(n=354)\end{array}$ & $\begin{array}{l}\text { VP+/VLBW- } \\
(n=144)\end{array}$ & $\begin{array}{l}\text { VP-/VLBW+ } \\
(n=207)\end{array}$ & $\begin{array}{l}\text { Overall } \\
p \text { value }\end{array}$ & $\begin{array}{l}\text { Nonresponders } \\
(n=254)\end{array}$ & $p$ value \\
\hline Male & $154(43.5)$ & $85(59.0)$ & $89(43.0)$ & $0.003^{\mathrm{a}, \mathrm{b}}$ & $169(66.5)$ & $<0.001$ \\
\hline Birth weight, $g$ & $1,161 \pm 211$ & $1,721 \pm 196$ & $1,275 \pm 175$ & $<0.001^{\mathrm{a}-\mathrm{c}}$ & $1,327 \pm 256$ & 0.387 \\
\hline Gestational age, weeks & $29.3 \pm 1.5$ & $30.7 \pm 1.0$ & $34.0 \pm 1.6$ & $<0.001^{\mathrm{a}-\mathrm{c}}$ & $31.2 \pm 2.7$ & 0.352 \\
\hline PROM & $82(23.2)$ & $37(25.7)$ & $8(3.9)$ & $<0.001^{\mathrm{b}, \mathrm{c}}$ & $47(18.5)$ & 0.862 \\
\hline Born via Cesarian section & $146(41.2)$ & $39(27.1)$ & $164(79.2)$ & $<0.001^{\mathrm{a}-\mathrm{c}}$ & $107(42.1)$ & 0.044 \\
\hline Apgar score $>7$ after $5 \mathrm{~min}$ & $279(78.8)$ & $125(86.8)$ & $185(89.4)$ & $0.003^{\mathrm{a}, \mathrm{b}}$ & $209(82.3)$ & 0.896 \\
\hline Duration of hospital stay, days & $79 \pm 31$ & $48 \pm 15$ & $59 \pm 25$ & $<0.001^{\mathrm{a}-\mathrm{c}}$ & $67 \pm 30$ & 0.996 \\
\hline Days of ventilation, $n$ & $7.3 \pm 10.0$ & $2.8 \pm 4.5$ & $1.7 \pm 8.9$ & $<0.001^{\mathrm{a}, \mathrm{b}}$ & $4.8 \pm 10.3$ & 0.887 \\
\hline IRDS & $181(51.1)$ & $66(45.8)$ & $29(14.0)$ & $<0.001^{\mathrm{b}, \mathrm{c}}$ & $97(38.2)$ & 0.788 \\
\hline Sepsis & $141(40.1)$ & $35(24.3)$ & $50(24.2)$ & $<0.001^{\mathrm{a}, \mathrm{b}}$ & $95(37.4)$ & 0.129 \\
\hline IVH & $91(25.7)$ & $22(15.3)$ & $13(6.3)$ & $<0.001^{\mathrm{a}-\mathrm{c}}$ & $39(15.4)$ & 0.362 \\
\hline NEC & $24(6.8)$ & $8(5.6)$ & $11(5.3)$ & 0.747 & $12(4.7)$ & 0.419 \\
\hline SGA & $36(10.2)$ & $2(1.4)$ & $159(76.8)$ & $<0.001^{\mathrm{a}-\mathrm{c}}$ & $75(29.5)$ & 0.631 \\
\hline
\end{tabular}

Values represent mean $\pm \mathrm{SD}$ or $n(\%)$. Continuous variables were compared with the one-way ANOVA test when comparing the 3 groups, and the independent $t$ test when comparing 2 groups. Dichotomous variables were compared with the $\chi^{2}$ test. VP, very preterm; VLBW, very low birth weight; PROM, premature rupture of the membranes; IRDS, infant respiratory distress syndrome; IVH, intraventricular hemorrhage; NEC, necrotizing enterocolitis; SGA, small-for-gestational-age.

${ }^{\mathrm{a}} p<0.05$ for $\mathrm{VP}+/ \mathrm{VLBW}+$ versus VP+/VLBW-.
${ }^{\mathrm{b}} p<0.05$ for $\mathrm{VP}+/ \mathrm{VLBW}+$ versus VP-/VLBW+.
${ }^{\mathrm{c}} p<0.05$ for VP+VLBW- versus VP-/VLBW+.

Occupation

Participants also provided details on their current occupation through self-report. Participation was coded as follows: no job or education (severe problem); part-time job $<16 \mathrm{~h} /$ week with no education, or part-time education without a job (moderate problem); part-time job 16-32 h/week, or part-time education with a job $<16 \mathrm{~h} /$ week (mild problem); and full-time education, full-time job $>32 \mathrm{~h} /$ week, or part-time education with a job 16-31 h/week (no problem).

Seventeen subjects did not correctly fill in the questionnaire, and their data were therefore excluded.

Health Status

The Health Utilities Index Mark 3 (HUI3) was used to determine health status and health-related quality of life. The HUI3 consists of 8 attributes, focusing on functional capacity: vision, hearing, speech, ambulation, dexterity, emotion, cognition, and pain. All attributes have 5 or 6 levels [19], which were dichotomized as "no problem" (levels $1+2$ ) and "moderate to severe problem" (level $\geq 3$ ) [4]. Subsequently, dichotomized attributes were combined as: 0 attributes affected (no problem), 1-2 attributes affected (mild problem), 3-4 attributes affected (moderate problem), or $\geq 5$ attributes affected (severe problem).

Perceived Health

The London Handicap Scale (LHS) was used to measure perceived health. It measures disadvantages for six dimensions on a 6-point hierarchical scale: mobility, physical independence (selfcare), occupation (daily activities), social integration, orientation, and economic self-sufficiency [20]. Coding of responses on the LHS was identical to the method used for the HUI3.

\section{Statistics}

Differences in functional outcomes, activities, and participation across the three groups were analyzed by multivariate linear or ordinal regression, depending on the measurement level of the outcome variable. Results were expressed as $\beta$ (95\% confidence interval [CI]) for linear regression, or odds ratio (OR) (95\% CI) for ordinal regression. Next, analyses were adjusted for: (1) gender, socioeconomic status, and ethnicity (Model 1); and (2) model 1 plus neonatal morbidities (infant respiratory distress syndrome, intraventricular hemorrhage, and sepsis) (Model 2). These confounders were selected based on the literature or on differences in baseline characteristics between the 3 groups (Table 1).

For measures yielding multiple outcomes (MCT, Touwen's examination of minor neurologic dysfunction, YASR, and YABCL), $\alpha$ was adjusted to 0.01 to reduce the risk for type 1 errors. For the other outcomes, $p<0.05$ was considered significant.

For all analyses, the VP+/VLBW+ group was used as the reference group.

\section{Results}

\section{Perinatal Characteristics}

At the age of 19 years, 959 of the 1,338 subjects were alive, and 705 of them (73.5\%) had been successfully followed up. Of the deceased, $96 \%$ had died within the first year of life (Fig. 1). The characteristics of responders and nonresponders did not significantly differ, except for 


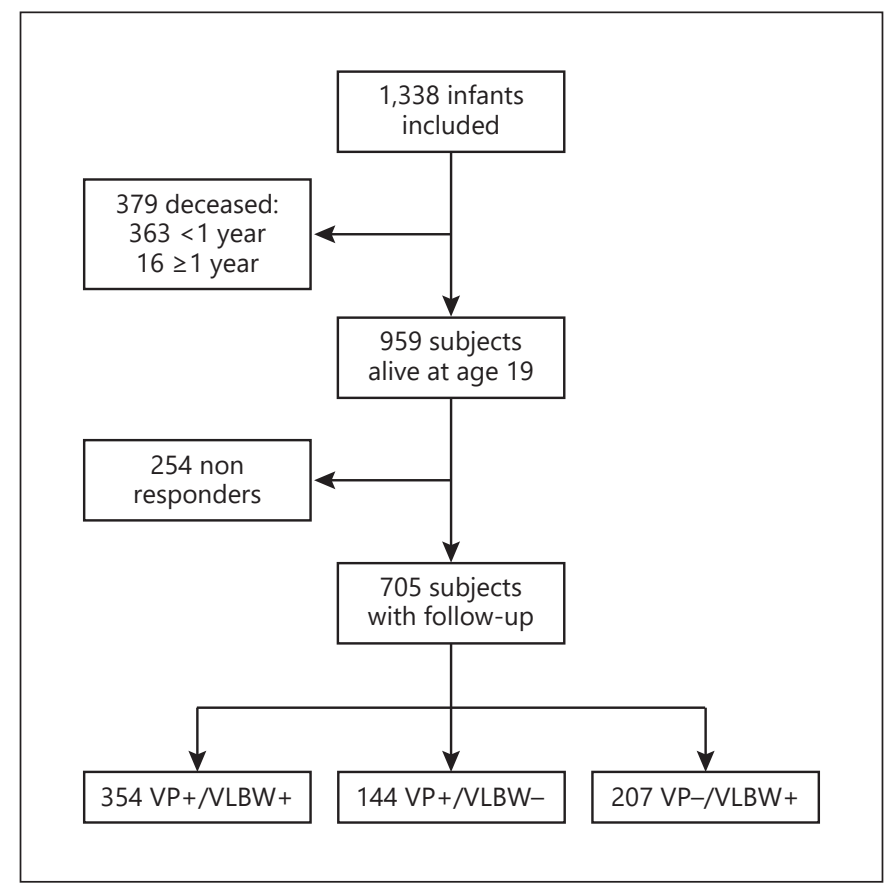

Fig. 1. Flowchart of the follow-up response of POPS subjects at the age of 19 years.

there being more males and slightly fewer Cesarian births among the latter (Table 1). The distribution of the subjects across the 3 groups was also not significantly different with regard to responders and nonresponders ( $p=$ 0.93).

Perinatal characteristics significantly differed in the 3 groups (Table 1). In general, infants in the VP-/VLBW+ group had fewer neonatal morbidities than the other 2 groups but were more often SGA. The VP+/VLBW+ group had the highest prevalence of neonatal morbidity, along with a longer hospital stay and more days on ventilation. The VP+/VLBW - group had the shortest hospital stay and the least SGA births.

\section{Neurodevelopmental Outcomes}

\section{Cognitive Functioning}

A trend towards a higher total IQ in the VP+/VLBWgroup versus the $\mathrm{VP}+/ \mathrm{VLBW}+$ group was observed (0.05 > $p>0.01$ ) (Table 2). No associations or trends were present in Models 1 and 2.

The subscore mathematical capacity was significantly higher in the VP+/VLBW- group. This association became nonsignificant $(p>0.01)$ in Models 1 and 2 .

\section{Neuromotor Function}

Total neuromotor score was comparable in the 3 groups (Table 2$)$. However, a trend $(0.05>p>0.01)$ towards a higher passive muscle tone subscore in the $\mathrm{VP}+$ / $\mathrm{VLBW}$ - group compared to the VP+/VLBW+ group was present, persisting in both models.

\section{Hearing Loss}

Hearing loss was significantly less for both the worst and best ear in the VP+/VLBW- group, in the crude and adjusted analyses (Table 2). No differences were found between the VP+/VLBW+ and VP-/VLBW+ groups.

\section{Behavioral and Emotional Functioning}

In the VP+/VLBW - group, the adolescents themselves and their parents reported lower scores on the Anxious/ depressed syndrome scale, as well as on the "Internalizing behavior" problem scale compared to the VP+/VLBW+ group (Table 3). The parents also reported fewer Attention problems. A trend $(0.05>p>0.01)$ towards fewer self-reported Attention problems as well as "Total problems" behavior was present in the VP+/VLBW- group. Most of these associations and trends were still present in both models. Adolescents in the VP-/VLBW+ group showed a trend towards a higher score on the Withdrawn behavior syndrome scale, both in the crude and adjusted analysis.

\section{Functional Outcomes}

Educational Achievement

No differences were found in worst-case coding education in the 3 groups (Table 2). However, a trend towards higher educational achievement in the $\mathrm{VP}+$ / VLBW- group than in the VP+/VLBW+ group appeared to be present. Repeated analyses for best-case coding found similar results (data not shown).

Occupation

No differences were found between the 3 groups (Table 2). Most subjects did not experience a problem with regard to occupation.

\section{Health Status}

The VP-/VLBW+ group had higher odds of reporting a lower health status than the VP+/VLBW+ group did (Table 2). This association remained significant in both models. 


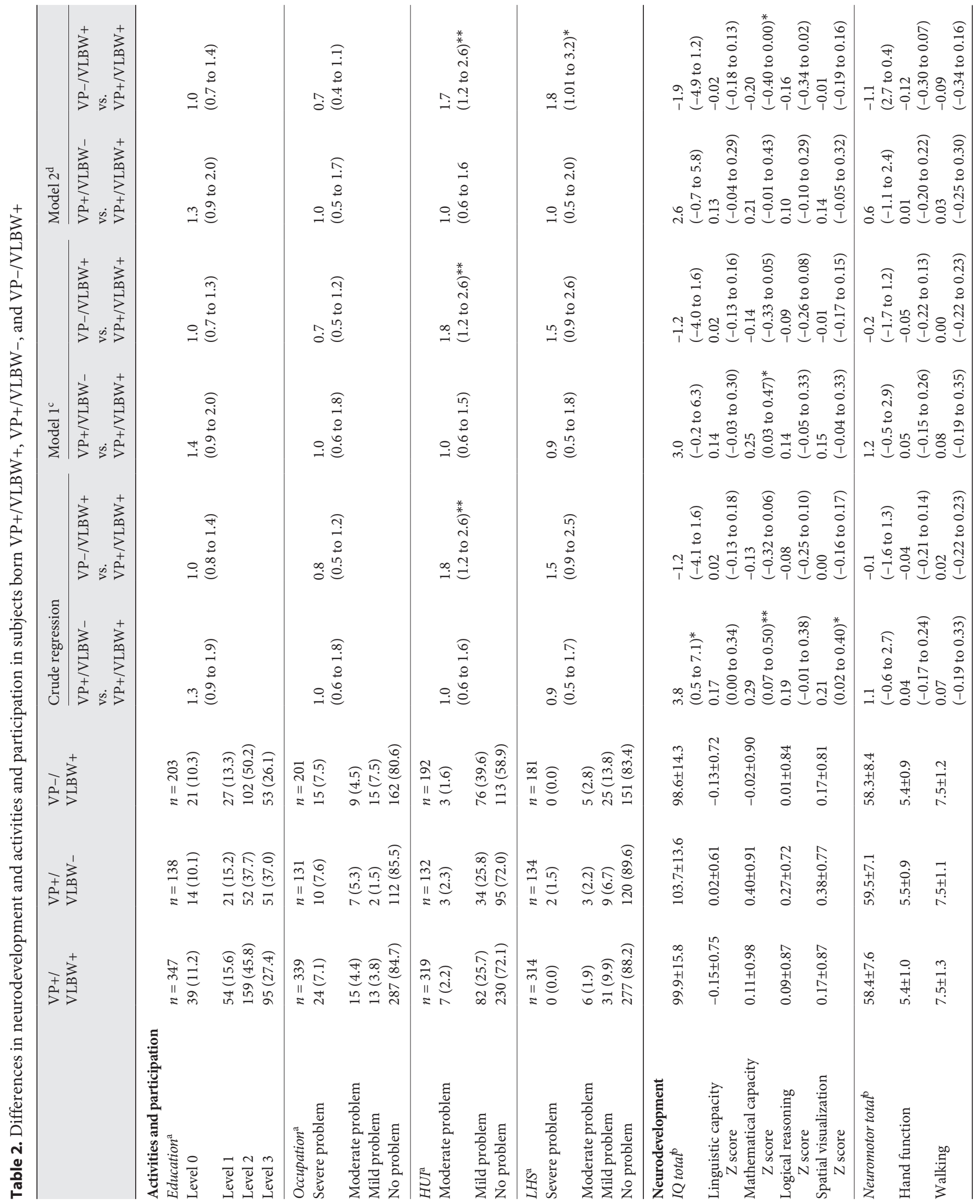




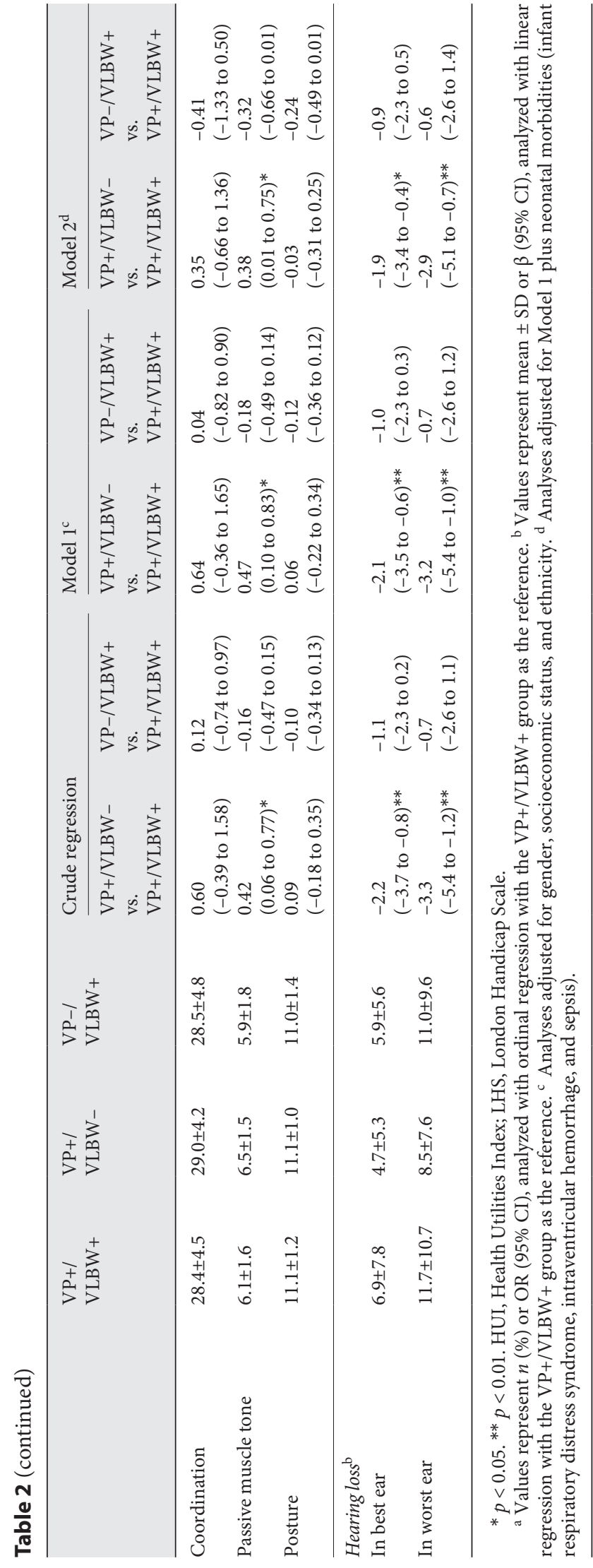

Perceived Health

No significant differences were found in the perceived health of the 3 groups (Table 2), although there was a nonsignificant tendency towards higher odds of reporting worse perceived health in the VP-/VLBW+ group (Table 2).

\section{Discussion}

In our study, we found that the long-term outcomes of $\mathrm{VP}+/ \mathrm{VLBW}$ - subjects were more favorable than those of $\mathrm{VP}+/ \mathrm{VLBW}+$ subjects. On average, the subjects in the $\mathrm{VP}+/ \mathrm{VLBW}$ - group had a trend towards a higher IQ score, as well as less hearing loss and less self- and parentreported behavioral problems. Additionally, a trend towards higher educational achievement was found in this group. Compared to the VP+/VLBW+ group, the VP-/ VLBW+ group reported worse self-perceived health. None of the observed differences were reflected in participants' occupational achievement.

Some associations became nonsignificant after correction for demographic and/or perinatal morbidity variables. Indeed, these factors have previously been identified as predictors for poor outcomes in preterm infants [21-24]. On the other hand, other associations remained significant after correction for these variables. However, it is unclear whether the loss of statistical significance for some associations was due to (appropriate) correction for confounding variables or (inappropriate) correction for intermediate variables in the causal pathway. Nevertheless, neurodevelopmental and functional outcomes still appeared significantly different in infants born $\mathrm{VP}+$ / VLBW+, VP+/VLBW-, and VP-/VLBW+ after analyses were adjusted for demographic and neonatal morbidity.

Our findings confirm that the entities VP and VLBW are not interchangeable. Previous research has shown that these two entities are associated with different shortterm outcomes [10], with a higher proportion of neonatal morbidities in the VP+/VLBW+ and VP+/VLBWgroups, but more SGA births in the VP-/VLBW+ group. Moreover, we have recently shown that different growth patterns up until final height are also present, with the best growth in VP+/VLBW- infants, while subjects in the VP-/VLBW+ group remain the shortest and lightest [11]. In this study, we also found differences in neurodevelopmental and functional outcomes between the terms VP and VLBW, contributing to the evidence that these two entities are indeed not the same. 


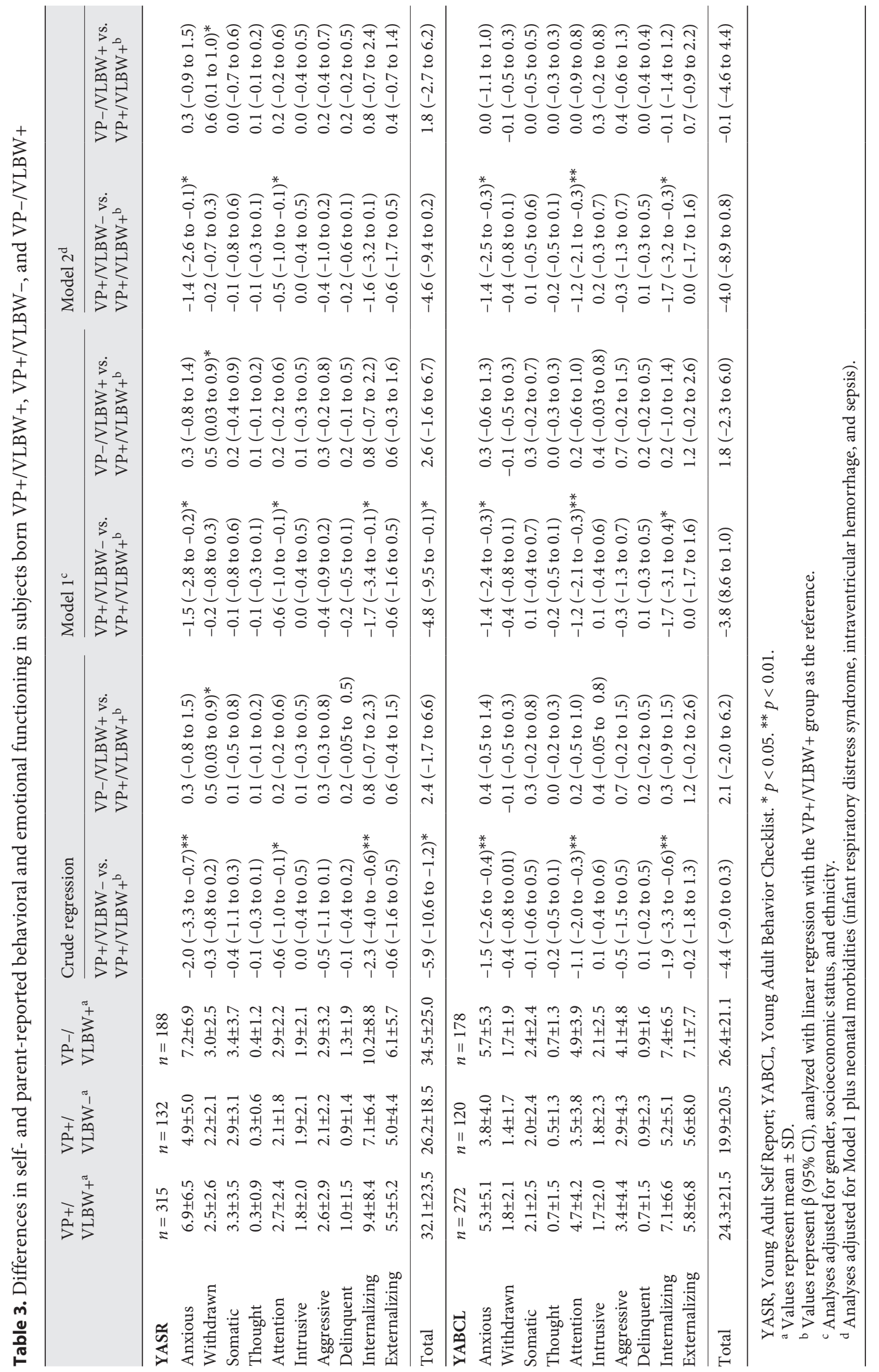


The differences found in our study were statistically significant, but the effect sizes were modest, and the differences in the three groups are also likely smaller than if the groups had been compared to a VP-/VLBWcontrol group. The clinical implications therefore remain to be determined. Our findings mostly have implications for (clinical) research. For future studies on preterm infants, we recommend using the same inclusion criteria, thereby enabling comparisons between cohorts. Previously, recommendations have been made to base epidemiologic studies on preterm infants on GA rather than on BW [25-28]. However, as far as we are aware, these studies only researched short-term (inhospital) outcomes. The results of our study on longterm neurodevelopmental differences, as well as our previous study on long-term growth outcomes, have added to the available evidence, showing that the differences between VP and VLBW subjects remain present into adolescence [11]. Therefore, since prematurity is defined by GA and since pregnancy duration can be measured accurately with current technology [29, 30], we concur with the previous recommendations that GA should be used as an inclusion criterion instead of BW, at least in industrialized countries. Simultaneously, we also recommend adjusting for BW SD scores when analyzing (long-term) outcomes, since BW is a strong determinant of long-term neurodevelopmental outcomes $[9,31,32]$.

The results of studies on VLBW infants cannot automatically be applied to a VP population, and vice versa; this should be taken into account when interpreting the results of a study on VP or VLBW infants. Nevertheless, the effect sizes found in our study were small, and VP and VLBW populations often do overlap with regard to clinical care. The substantial established body of literature, on both VP and VLBW subjects, therefore remains extremely valuable. However, especially as infants with increasingly younger GA are now being treated, we recommend that future studies select preterm populations primarily based on GA.

Our study has several strengths and limitations. Its major strengths are its large sample size, long-term follow-up, the analytical approach that adjusted for multiple potential confounders, and the use of a broad range of neurodevelopmental and functional outcomes. It also has its limitations. Although we found several differences in neurodevelopmental and functional outcomes in the 3 groups, the mechanism behind these differences cannot be elucidated with the available data, since the etiology of these outcomes is most likely complex and

Neurodevelopment in VP versus VLBW Infants multifactorial. Additionally, since 1983, improvements in neonatal care have been made, while infants with an increasingly younger GA are being treated, and intrauterine growth is better monitored. A VP and/or VLBW cohort is therefore likely to have a different composition nowadays, and the results of this study, as well as the etiology behind these results, can therefore not necessarily be applied to the current generation of preterm infants. However, while mortality has decreased, morbidity has increased [12], which could entail a higher risk for adverse neurodevelopmental and functional outcomes. Moreover, using either VP or VLBW as an inclusion criterion will most likely still lead to different outcomes. Additionally, we performed multiple statistical tests, and so it is possible that some of the associations were due to chance, even after adjusting the $\alpha$ to 0.01 for measures that yielded multiple outcomes. Our results should therefore be interpreted with caution. Lastly, the gender distribution differed between responders and nonresponders. However, since none of the other characteristics, as well as the distribution of subjects across groups, were different, it is unlikely that our results were subject to attrition bias, although this cannot be ruled out.

In conclusion, subjects born $\mathrm{VP}+/ \mathrm{VLBW}+, \mathrm{VP}+/$ VLBW-, and VP-/VLBW+ had significantly different neurodevelopmental and functional outcomes, although effect sizes were small. Moreover, previous research has shown that the terms VP and VLBW also lead to different short- and long-term outcomes [10,11], indicating that these entities are not the same. We recommend, at least in industrialized countries, that inclusion for future studies in preterm populations be based on GA instead of BW.

\section{Acknowledgements}

We acknowledge the participants in the Dutch POPS-19 Collaborative Study Group: TNO Quality of Life, Leiden (E.T.M. Hille, C.H. de Groot, H. Kloosterboer-Boerrigter, A.L. den Ouden, A. Rijpstra, S.P. Verloove-Vanhorick, J.A. Vogelaar); Emma Children's Hospital AMC, Amsterdam (J.H. Kok, A. Ilsen, M. van der Lans, W.J.C. Boelen-van der Loo, T. Lundqvist, H.S.A. Heymans); University Hospital Groningen, Beatrix Children's Hospital, Groningen (E.J. Duiverman, W.B. Geven, M.L. Duiverman, L.I. Geven, E.J.L.E. Vrijlandt); University Hospital Maastricht, Maastricht (A.L.M. Mulder, A. Gerver); University Medical Center St Radboud, Nijmegen (L.A.A. Kollée, L. Reijmers, R. Sonnemans); Leiden University Medical Center, Leiden (J.M. Wit, F.W. Dekker, M.J.J. Finken); Erasmus MC - Sophia Children's Hospital, University Medical Center Rotterdam (N. Weisglas-Kuperus, M.G. Kei- 
jzer-Veen, A.J. van der Heijden, J.B. van Goudoever); V.U. University Medical Center, Amsterdam (M.M. van Weissenbruch, A. Cranendonk, H.A. Delemarre-van de Waal, L. de Groot, J.F. Samsom); Wilhelmina Children's Hospital, UMC, Utrecht (L.S. de Vries, K.J. Rademaker, E. Moerman, M. Voogsgeerd); Máxima Medical Center, Veldhoven (M.J.K. de Kleine, P. Andriessen, C.C.M. Dielissen-van Helvoirt, I. Mohamed); Isala Clinics, Zwolle (H.L.M. van Straaten, W. Baerts, G.W. Veneklaas Slots-Kloosterboer, E.M.J. Tuller-Pikkemaat); Royal Effatha Guyot Group, Zoetermeer (M.H. Ens-Dokkum); Association for Parents of Premature Babies (G.J. van Steenbrugge).

\section{Statement of Ethics}

Ethics approval of all participating centers was obtained.

\section{Disclosure Statement}

The authors have nothing relevant to this article to disclose.

\section{Funding Sources}

The authors did not receive funding for this particular article. The POPS-19 follow-up was supported by grants from the Netherlands Organisation for Health Research and Development (ZonMw), Edgar Doncker Foundation, Foundation for Public Health Fundraising Campaigns, Phelps Foundation, Swart-van Essen Foundation, Foundation for Childrens Welfare Stamps, TNO Prevention and Health, Netherlands Organisation for Scientific Research (NWO), Dutch Kidney Foundation, Sophia Foundation for Medical Research, Stichting Astmabestrijding, Royal Effatha Guyot group.

\section{References}

1 Aarnoudse-Moens CS, Weisglas-Kuperus N, van Goudoever JB, Oosterlaan J. Meta-analysis of neurobehavioral outcomes in very preterm and/or very low birth weight children. Pediatrics. 2009 Aug;124(2):717-28.

2 Nosarti C, Giouroukou E, Micali N, Rifkin L, Morris RG, Murray RM. Impaired executive functioning in young adults born very preterm. J Int Neuropsychol Soc. 2007 Jul;13(4): 571-81.

3 Hille ET, Dorrepaal C, Perenboom R, Gravenhorst JB, Brand R, Verloove-Vanhorick SP. Social lifestyle, risk-taking behavior, and psychopathology in young adults born very preterm or with a very low birthweight. J Pediatr. 2008;152:793-800.

4 Hille ET, Weisglas-Kuperus N, van Goudoever JB, Jacobusse GW, Ens-Dokkum MH, de Groot L, et al; Dutch Collaborative POPS 19 Study Group. Functional outcomes and participation in young adulthood for very preterm and very low birth weight infants: the Dutch Project on Preterm and Small for Gestational Age Infants at 19 years of age. Pediatrics. 2007 Sep;120(3):e587-95.

5 Hack M, Youngstrom EA, Cartar L, Schluchter M, Taylor HG, Flannery D, et al. Behavioral outcomes and evidence of psychopathology among very low birth weight infants at age 20 years. Pediatrics. 2004 Oct;114(4):932-40.

6 Hack M, Cartar L, Schluchter M, Klein N, Forrest CB. Self-perceived health, functioning and well-being of very low birth weight infants at age 20 years. J Pediatr. 2007;151:63541.

7 Darlow BA, Horwood LJ, Pere-Bracken HM, Woodward LJ. Psychosocial outcomes of young adults born very low birth weight. Pediatrics. 2013 Dec;132(6):e1521-8.
8 Saigal S. Quality of life of former premature infants during adolescence and beyond. Early Hum Dev. 2013 Apr;89(4):209-13.

9 Pyhälä R, Lahti J, Heinonen K, Pesonen AK, Strang-Karlsson S, Hovi P, et al. Neurocognitive abilities in young adults with very low birth weight. Neurology. 2011 Dec;77(23): 2052-60.

10 Lapeyre D, Klosowski S, Liska A, Zaoui C, Gremillet C, Truffert $P$. [Very preterm infant ([\{LT\}] 32 weeks) vs very low birth weight newborns (1500 grammes): comparison of two cohorts]. Arch Pediatr. 2004 May;11(5): 412-6.

11 Hollanders JJ, van der Pal SM, van Dommelen P, Rotteveel J, Finken MJ. Growth pattern and final height of very preterm vs. very low birth weight infants. Pediatr Res. 2017 Aug;82(2): $317-23$.

12 Stoelhorst GM, Rijken M, Martens SE, Brand R, den Ouden AL, Wit JM, et al; Leiden Follow-Up Project on Prematurity. Changes in neonatology: comparison of two cohorts of very preterm infants (gestational age 32 weeks): the Project on Preterm and Small for Gestational Age Infants 1983 and the Leiden Follow-Up Project on Prematurity 19961997. Pediatrics. 2005 Feb;115(2):396-405.

13 Serenius F, Sjörs G, Blennow M, Fellman V, Holmström G, Maršál $K$, et al.; EXPRESS study group. EXPRESS study shows significant regional differences in 1-year outcome of extremely preterm infants in Sweden. Acta Paediatr. 2014 Jan;103(1):27-37.

14 Bleichrodt N, Berg RH. Multicultural Capacity Test: Intermediate Level (MCT-M) Manual. Amsterdam: NOA; 2000.

15 Samsom JF, de Groot L, Cranendonk A, Bezemer D, Lafeber HN, Fetter WP. Neuromotor function and school performance in 7-yearold children born as high-risk preterm infants. J Child Neurol. 2002 May;17(5):325-32.
16 Touwen BC. The Examination of the Child with Minor Neurological Dysfunction: Clinics in Developmental Medicine Series. London: Heinemann; 1979.

17 Achenbach TM. Manual for the young adult self-report and young adult behavioral checklist. Burlington: University of Vermont Department of Psychiatry; 1997.

18 Standaard Onderwijsindeling Centraal Bureau voor de Statistiek; 2006, ed 2014/'15.

19 Feeny D, Furlong W, Torrance GW, Goldsmith CH, Zhu Z, DePauw S, et al. Multiattribute and single-attribute utility functions for the health utilities index mark 3 system. Med Care. 2002 Feb;40(2):113-28.

20 Harwood RH, Rogers A, Dickinson E, Ebrahim S. Measuring handicap: the London Handicap Scale, a new outcome measure for chronic disease. Qual Health Care. 1994 Mar; 3(1):11-6.

21 den Ouden L, Verloove-Vanhorick SP, van Zeben-van der Aa DM, Brand R, Ruys JH. Neonatal neurological dysfunction in a cohort of very preterm and/or very low birthweight infants-relation to other perinatal factors and outcome at 2 years. Neuropediatrics. 1990 May;21(2):66-71.

22 Doyle LW, Cheong JL, Burnett A, Roberts G, Lee KJ, Anderson PJ; Victorian Infant Collaborative Study Group. Biological and Social Influences on Outcomes of Extreme-Preterm/ Low-Birth Weight Adolescents. Pediatrics. 2015 Dec;136(6):e1513-20.

23 Mitha A, Foix-L'Hélias L, Arnaud C, Marret S, Vieux R, Aujard Y, et al.; EPIPAGE Study Group. Neonatal infection and 5-year neurodevelopmental outcome of very preterm infants. Pediatrics. 2013 Aug;132(2):e372-80. 
24 Wong HS, Edwards P. Nature or nurture: a systematic review of the effect of socio-economic status on the developmental and cognitive outcomes of children born preterm. Matern Child Health J. 2013 Nov; 17(9):1689700.

25 Arnold CC, Kramer MS, Hobbs CA, McLean FH, Usher RH. Very low birth weight: a problematic cohort for epidemiologic studies of very small or immature neonates. Am J Epidemiol. 1991 Sep;134(6):604-13.

26 Blair $\mathrm{E}$. The undesirable consequences of controlling for birth weight in perinatal epidemiological studies. J Epidemiol Community Health. 1996 Oct;50(5):559-63.
27 Koller-Smith LI, Shah PS, Ye XY, Sjörs G, Wang YA, Chow SS, et al.; Australian and New Zealand Neonatal Network; Canadian Neonatal Network; Swedish Neonatal Quality Register. Comparing very low birth weight versus very low gestation cohort methods for outcome analysis of high risk preterm infants. BMC Pediatr. 2017 Jul;17(1):166.

28 Mohangoo AD, Blondel B, Gissler M, Velebil P, Macfarlane A, Zeitlin J; Euro-Peristat Scientific Committee. International comparisons of fetal and neonatal mortality rates in high-income countries: should exclusion thresholds be based on birth weight or gestational age? PLoS One. 2013 May;8(5):e64869.
29 Mongelli M, Wilcox M, Gardosi J. Estimating the date of confinement: ultrasonographic biometry versus certain menstrual dates. Am J Obstet Gynecol. 1996 Jan;174(1 Pt 1):278-81.

30 Neilson JP. Ultrasound for fetal assessment in early pregnancy. Cochrane Database Syst Rev. 2000;(2):CD000182.

31 Hack M, Flannery DJ, Schluchter M, Cartar L, Borawski E, Klein N. Outcomes in young adulthood for very-low-birth-weight infants. N Engl J Med. 2002 Jan;346(3):149-57.

32 Saigal S. Follow-up of very low birthweight babies to adolescence. Semin Neonatol. 2000; 5:107-18. 